\title{
BACKSTROKE TEACHING METHODS IN HEALTHY CHILDREN WITH RESIDUAL PRIMITIVE REFLEXES
}

\author{
Irina Bogdanovica \\ Latvian Academy of Sport Education, Latvia \\ Viesturs Larins \\ Latvian Academy of Sport Education, Latvia
}

\begin{abstract}
There are studies suggesting that primitive reflexes can remain active in healthy children. Formal backstroke teaching is a part of many aquatic curriculum program. Even though the links with a problem during swimming learning with retained primitive reflexes were mentioned, there are no studies about effect of different backstroke teaching methods in healthy children with residual primitive reflexes. Aim of the study is to define the effect of teaching methods for backstroke in healthy children with residual primitive reflexes. Subjects: 6-7 years old healthy children with residual primitive reflexes. Methods: A part practice backstroke teaching method for the first group (12 children) has been focused on teaching of separate components (leg kicks, arm pulls, and breathing) before fitting them together, while another 12 participants in second group learnt backstroke separate components of arm-to-leg integration before combining them together inside of cycle. After 12 weeks of practice backstroke proficiency and heart rate during maximal continuous backstroke swimming were analyzed. The obtained results show significant differences between the two groups. The results of the second group are linked with better backstroke proficiency, significantly longer swimming distance and lower heart rate during swimming.
\end{abstract}

Keywords: backstroke teaching methods, primitive reflexes.

\section{Introduction}

Formal swimming stroke is taught during swimming lessons with the expectation that it would provide individual water safety and will be useful during the whole lifetime (Revesz, Bognar, Salvara, Gita \& Biro, 2007; Franklin et al., 2015). Formal backstroke requires high levels of intralimb and interlimb interaction, with the body rolling around the longitudinal axis, a horizontal body position and breathing skill (Maglischo, 2003; Riewald \& Rodeo, 2015). In this context the ability to coordinate both sides of the body in the learning of backstoroke movements play a crucial role. The bilateral interaction between the swimmers' moving limbs is characterized by common in-phase coordinative mode between the key events of arms and legs. Besides, this common form includes a diagonal interlimb pattern, where the limbs (e.g., arms and legs) on 
opposite sides of the body move in unison (Maglischo, 2003; Martínez-Sobrino, Veiga, \& Navandar, 2017).

Formal backstroke swimming, as a rational sequential chain of movements (Maglischo, 2003), could be considered as a skill with high motor task complexity and the part practice method should be used for this task (Fontana et al., 2009) in order to reduce cognitive load in the early stage of learning (Wulf \& Shea, 2002; Magill \& Anderson, 2016). Part practice mode for swimming stroke acquisition is traditionally focused on the teaching pattern of backstroke movements' separate components, broken down into sequential steps (leg kicks, arm movements and breathing). Each component is taught independently before fitting them all together to produce the whole common pattern of coordination at a later stage of practice (Blanksby, Parker, Bradley \& Ong, 1995; Oh, Licari, Lay, \& Blanksby, 2011). In this case, the instructor's implicit assumption is that sensorimotor adaptation will developed the ability to combine all backstroke movements into common pattern of limbs bilateral interaction through trial and error Maglischo, 2003; Invernizzi et al., 2006, Langendorfer, 2007). Sensorimotor adaptation means the integration of incoming extero- or intero-receptive sensory information into motor responses to produce a consistent movement (Gomez \& Sirigu, 2015). One factor that may reduce children's ability to process sensory information effectively and decrease a cognitive load is the residual presence of primitive reflexes (Blythe, 2011; Pecuch et al., 2020). Primitive reflexes are involuntary movements in response to a specific stimulus (Sohn, Ahn \& Lee, 2011). They are represented at birth in the full-term neonate, gradually get inhibited and should not remain active in the general population beyond one year of age (Schott \& Rossor, 2003; Zafeiriou, 2004; Sharma, Ford, \& Calvert, 2014). The studies suggest that primitive reflexes can remain active as residual reflexes in about $90 \%$ of healthy preschool and more than $50 \%$ of elementary school-age children (Gieysztor, Sadowska \& Choińska, 2017; Gieysztor, Choińska, \& PaprockaBorowicz, 2018). The presence of residual primitive reflexes affects the bilateral upper-and lower-body integration, the muscle tone, balance and coordination (Blythe, 2011; Gieysztor, Choińska, \& Paprocka-Borowicz, 2018). "Retained reflexes become impediments to or even prevent volitional moves or specific motor abilities" (Krzeszewska \& Mikołajewska, 2018). Although the links to problems during swimming learning and retained primitive reflexes have been mentioned (Blythe, 2011; Bilbilaj, Gjipali, \& Shkurti, 2017), there are no studies about the effect of different teaching methods of swimming strokes in healthy children with residual primitive reflexes (RPR). Therefore, it is important to seek strategies that prevent difficulties which children with RPR might encounter during swimming learning. Regarding to backstroke swimming learning, residual primitive reflexes could constraint the ability to acquire common pattern of coordination. In this context, the part practice strategy directly aimed on acquiring 
the common form of key interaction of arms and legs could be more effective and preferable during backstroke swimming teaching in healthy children with RPR. The aim of the study is to define the effect of teaching methods for backstroke in healthy children with residual primitive reflexes.

\section{Methodology}

\section{Participants and procedure}

Quasi-experimental designs were used due to the fact that random selection of groups cannot be achieved. The two parallel groups were matched as closely as possible and were experimented on to compare the consistency of the outcomes (Walliman, 2011). The participants in this study were two groups with twelve subjects of 6 - 7-year-old healthy children with residual primitive reflexes. Before the start of the study, the children's parents signed the written informed consent form. All participants' health condition were defined by their General Practitioner as "practically healthy" and had no medical histories in terms of both neurodevelopmental disorders as well as cardiovascular disorders. In this age group there are no significant differences, both in cognitive development as well as motor abilities between genders (female and male) (Ardila et al., 2011; Polimac, Vukadinovic, \& Obradovic, 2013). Additionally, there were no significant differences between the two groups of children $(p<0.05)$ in relation to age, body mass index, the degree of primitive reflexes integration and level of aquatic skill before the lessons. The present study has been focused on the three primitive reflexes due to their impact on coordination and balance (Blythe, 2009), which are crucial in swimming stroke acquisition. The testing of the primitive reflexes (asymmetrical tonic neck reflex, the symmetrical tonic neck reflex, and the tonic labyrinthine reflex) was done using Blythe's 5-point rating scale (0-4). The maximal total scores for primitive reflexes were the summation of the scores of each reflexes (24 points) and were represented as the degree of primitive reflex integration (Gieysztor, Choińska, \& Paprocka-Borowicz, 2018). To participate in the present study all kids must have been able to perform certain aquatic skill components, but not proficient in backstroke. Competence was required in submerging (complete submersion on own without hesitation), blowing bubbles (blow bubbles with whole face in water), back float (stretched body), front float (stretched body), gliding (reasonably straight legs) (Blanksby et al., 1995).

The present study was carried out in a 25-meter long and variably deep swimming pool. The depth ranged from $1.80 \mathrm{~m}$ in the shallow part to $2.50 \mathrm{~m}$ in the deep, water temperature was $28-29^{\circ} \mathrm{C}$. The classes of two students per teacher were formed for 12 lessons, which they attended once a week for 30 minutes. The lessons were held at the same time of the day and day of the week, between 15:00 and 17:15 conditional on maintaining the sequence of the implementation of the program of various methods of teaching backstroke. During the study, children 
had the opportunity to attend other days and times if they did not attend class at their usual time. Attendance at all lessons was required for results to be included.

The part practice teaching method for 12 participants in first group was aimed at the individual components of backstroke movements already applied by Oh et al., (2011) and widely recommended by swimming learning textbooks. The teaching of body position, legs movement, arms movement and breathing were broken down into sequential steps. Horizontal body position with breathing and flutter kick was practiced first before arms movements were each added. Then, the whole stroke was practiced by combining the arms, breathing, and kicking actions (Table 1).

Table 1 Focus of Attention on Teaching

Pattern of Backstroke Movements (BM) in the First Group

\begin{tabular}{|c|l|}
\hline Backstroke & \multicolumn{1}{|c|}{ Backstroke individual components } \\
\hline The body position & $\begin{array}{l}\text { BM1. - horizontal aligment of the trunk in water; BM2. - tummy pushed } \\
\text { up; BM3. - minimal body rotation; }\end{array}$ \\
\hline $\begin{array}{c}\text { Head position and } \\
\text { breathing }\end{array}$ & $\begin{array}{l}\text { BM4. - head remains horizontal in water, with eyes looking up to the } \\
\text { top; BM5. - coordinated one complete breathing cycle to the rhythm of } \\
\text { motion; }\end{array}$ \\
\hline $\begin{array}{c}\text { Use of upper } \\
\text { limbs }\end{array}$ & $\begin{array}{l}\text { BM6. - fingers are closed together; BM7. - slow, straight arm } \\
\text { backstroke; BM8. - little finger leads and enters water first; BM9. - hand } \\
\text { pull through and exits water at upper thigh level; }\end{array}$ \\
\hline $\begin{array}{c}\text { Use of lower } \\
\text { limbs }\end{array}$ & $\begin{array}{l}\text { BM10. - kick initiated at the hips; BM11. - knees extended with straight } \\
\text { legs kicking action; BM12. - relaxed feet with ankles pointed down; } \\
\text { BM13. - kicking feet just break surface; }\end{array}$ \\
\hline
\end{tabular}

The part practice strategy for 12 children in second group was aimed at the teaching of the common form of coordination broken down into sequential steps. Following the backstroke coordination model proposed by Maglischo (2003), we adapted key instants of the diagonal interaction between the arm movement and the leg kicking inside each cycle. Horizontal body position and interaction of one complete breathing cycle with six beat leg kicks was practiced first before separate components of bilateral interaction between arms and legs within the cycle were added. For example, an upkick of a leg accompanied by an ipsilateral arm clearing phase was practiced first in backstroke before another appropriate characteristics between arms and legs movements defining the common pattern of coordination were added. Then, the whole stroke was practiced by combining breathing and key instants of the backstroke cycle components (Table 2). 
SOCIETY. INTEGRATION. EDUCATION

Proceedings of the International Scientific Conference. Volume IV, May $28^{\text {th }}-29^{\text {th }}$, 2021. 318-332

Table 2 Focus of Attention on Teaching Backstroke

Common Pattern of Coordination (BC) in the Second Group

\begin{tabular}{|c|l|}
\hline Backstroke components & Backstroke individual components of the cycle \\
\hline The body position & $\begin{array}{l}\text { BM1. - horizontal aligment of the trunk in water; BM2. - tummy } \\
\text { pushed up. }\end{array}$ \\
\hline $\begin{array}{c}\text { Head position and } \\
\text { breathing }\end{array}$ & $\begin{array}{l}\text { BM4. - head remains horizontal in water, with eyes looking up } \\
\text { to the top; BM5. - coordinated one complete breathing cycle to } \\
\text { the rhythm of motion. }\end{array}$ \\
\hline $\begin{array}{c}\text { A bilateral interaction } \\
\text { between arms and legs } \\
\begin{array}{c}\text { with six-beat kick per } \\
\text { cycle/ arm-to-leg } \\
\text { diagonal interaction }\end{array}\end{array}$ & $\begin{array}{l}\text { BC14. - a upkick of the leg accompanies the contralateral arm } \\
\text { recovery phase and the ipsilateral arm backward movement; } \\
\text { BC15. - an upkick of the leg accompanies the contralateral arm } \\
\text { backward movement; BC16. - an upkick of the leg accompanies } \\
\text { the ipsilateral arm clearing phase. }\end{array}$ \\
\hline
\end{tabular}

For each swimming lesson, participants performed set of 25m practice trials (exercises). Verbal and visual feedback was specific to the needs of each individual to facilitate optimal learning. Before beginning each swimming exercise, each kid was provided with some initial instruction on how to perform a movement. First, she or he viewed a visual model of a correct swimming movement shown by the teacher followed by verbal instructions regarding correct movement technique. During each exercise, participants received one of two feedback statements respective to their attentional focus condition following every trial (see Table 2 and 3). Each statement depended on the basis of each participant's performance from the preceding trials. Importance of adopting this attentional focus during performance of the next exercise was communicated to each participant. Both swimming buoyancy aids (belts) as well as stoke mastery aids like kickboards were used to assist with the learning progress. To increase the objectivity of the assessment, the instruction for children to perform each aquatic skill was given by the same experienced instructor in both groups. All instructions and feedback throughout the experiment were given by the teachers who had Master Degree in pedagogical education and appropriate academic qualifications for teaching swimming with 15 years of professional experience in teaching of swimming.

To analyze the effect of different teaching methods, backstroke skilled actions were evaluated at swimming lesson 4 and after 12 practice lessons. During testing, one trial was used for assessment skill consistency as well as efficiency (Muratori, Lamberg, Quinn, \& Dufl, 2013). Participants received the visual and verbal cues as a reminder of the instructions once more and were asked to perform at their best ability. No buoyancy aids were used during the assessment. 


\section{Measures}

To define the effect of different backstroke teaching methods, it is important to objectively evaluate how a child attained that skill. In present study, skilled actions were assessed by both their consistency as well as their efficiency (Muratori et al., 2013).

All children were evaluated for their consistency (Muratori et al., 2013) of backstroke proficiency (BP) using an observation checklist of 16 individual components mentioned in Tables 2 and 3 . Each component was rated on a four point scale: $1=$ Not at all; $2=$ Sometimes; $3=$ Most of the time; $4=$ All the time. For both groups data was collected from the assessment of the maximal total score for both backstroke movement proficiency (BM) as well as for backstroke common pattern of coordination (BC). The maximal total score for BM was the summation of the scores of each stroke's individual component (BM1 to BM13) and the maximal total score for $\mathrm{BC}$ was the summation of the scores of cycle key instants (BC14 to BC16). The maximal total score for Backstroke Proficiency (BP) was the summation of the scores both BM as well as BC and were represented as a percentage of the possible maximal score (64 points).

The components of backstroke skilled movements' efficiency (Muratori et al., 2013) included the possibility to swim certain distance and the heart rate response during a task performance. All children were verbally encouraged to continue swimming until volitional exhaustion. The termination criterion of maximal distance of backstroke swimming is simply when the subject fails to execute exercise for the next $25 \mathrm{~m}$. The 1 point was given for each covered $25 \mathrm{~m}$ distance. Common score correspondent to maximal continuously swimming amount of $25 \mathrm{~m}$ trials. Heart rate (HR) was assessed with a cardiac rhythm monitor adjusted around the child's chest.

Standard statistical methods for all variables were used for the calculation of means and standard deviations or percentages. The distribution of each variable was examined with the Kolmogorov-Smirnov normality test and after that a paired t-test for two independent means was used to assess the differences of variables between two groups. The t test for two dependent means was used to compare the differences of two sets of scores that are directly related to each other. The effect size was calculated with the Cohen's d (Cohen, 1988). Statistical significance for all the comparisons was set at $\mathrm{p}<0.05$. All data analysis was carried out using Microsoft Excel and SPSS spreadsheet applications.

\section{Results}

The participants of present study were two groups of healthy children with residual primitive reflexes (RPR). To ensure the subjects had enough rest, we measured the heart rate before the backstroke skilled action assessment. There 
were no significant differences between the two groups of children $(p<0.05)$ in relation to heart rate before testing. Besides, the subjects were authorized to swim if they were within the normal range of heart rate rest values, i.e. between 80 and 105 beat per minutes (Fleming et al., 2011). At the beginning of the present study, no differences were found in backstroke between two groups. The participants were not performing backstroke individual components and their backstroke proficiency was zero in all components.

At the 4 weeks of the present study, no significant differences were found in the all backstroke skilled movements components between two groups $(\mathrm{p}<.05)$. The participants of both group acquired the certain level of backstroke mastery, nevertheless their backstroke proficiency in common pattern of coordination (BC) was zero (3.00 \pm 0.00$)$. The first group results in $\mathrm{BM}$ and $\mathrm{BP}$ was $28.65 \pm 3.67$ points and $31.75 \pm 3.67$ points subsequently, Dmax was $0.83 \pm 0.39$ points and HR response during testing was $163.3 \pm 5.3 \mathrm{bpm}$. The second group demonstrated $29.42 \pm 3.70$ points in BM proficiency and $32.42 \pm 3.70$ points in BP proficiency, Dmax was $0.58 \pm 0.51$ and the HR of children reached $160.1 \pm 7.7 \mathrm{bpm}$. The effect size (Cochen's d) of the differences in BM, BP, Dmax and HR was 0.21, 0.18, 0.55 and 0.48 subsequently.

Table 3 presents the results of assessment backstroke skilled movements components demonstrated by two groups after twelve weeks of teaching.

Table 3 Backstroke Skilled Movement Components (mean \pm SD) after Twelve Weeks of Teaching

\begin{tabular}{|c|c|c|c|c|}
\hline Components & $\begin{array}{c}\text { The first } \\
\text { group } \\
\text { (mean } \pm \text { SD) }\end{array}$ & $\begin{array}{c}\text { The second } \\
\text { group } \\
\text { (mean } \pm \text { SD) }\end{array}$ & p - value & Cochen's d \\
\hline BM & $42.92 \pm 4.12$ & $40.5 \pm 3.57$ & 0.069 & 0.436 \\
\hline BC & $3.58 \pm 0.29$ & $11.25 \pm 1.36$ & $\mathrm{p}<0.05^{*}$ & 7.815 \\
\hline BP & $46.5 \pm 4.54$ & $51.75 \pm 4.58$ & $\mathrm{p}<0.05^{*}$ & 1.149 \\
\hline Dmax & $7.92 \pm 2.43$ & $15.58 \pm 3.00$ & $\mathrm{p}<0.05^{*}$ & 2.804 \\
\hline $\begin{array}{c}\text { HR during test } \\
\text { (bpm) }\end{array}$ & $154.25 \pm 5.05$ & $126.92 \pm 8.83$ & $\mathrm{p}<0.05^{*}$ & 3.799 \\
\hline
\end{tabular}

Note. ${ }^{*}=$ significantly different between measures; HR=heart rate; $b p m=$ beat per minute; Dmax = maximal continuously swimming amount of $25 \mathrm{~m}$ trials; $B M=$ Backstroke movements proficiency; $B C=$ Backstroke common pattern of coordination proficiency; BP - Backstroke proficiency (the summation of the scores both $B M$ as well as $B C$ ). 
During twelve weeks of backstroke skill learning the first group showed significant progress in backstroke proficiency (BP) of $22 \%$ - from $31.75 \pm 3.67$ to $46.5 \pm 4.54$ points, which indicates $50 \%$ and $72 \%$ of the possible maximal score consequently $(p<.05)$. After 12 weeks of teaching the group showed significant improvement both in BM acquisition from $28.65 \pm 3.67$ to $42.92 \pm 4.12$ points as well as Dmax from $0.83 \pm 0.39$ to $7.92 \pm 2.43$ points. The level of BC proficiency (3.58 \pm 0.29$)$ remained without significant changes and HR significantly decreased from 163.3 $\pm 5.3 \mathrm{bpm}$ to $154.3 \pm 5.1 \mathrm{bpm}(\mathrm{p}<.05)$. The second group backstroke proficiency became $30 \%$ higher, i.e. $32.42 \pm 3.7$ to $51.75 \pm 4.58$ points which made up for $51 \%$ and $81 \%$ of the possible maximal score consequently $(p<.05)$. The group showed significant progress both in BM acquisition: from 29.42 \pm 3.70 to $40.5 \pm 3.5$ points as well as BC proficiency: from $3.00 \pm 0.00$ to $11.25 \pm 1.36$ points $(\mathrm{p}<.05)$. Additionally, the results of Dmax significantly increased: from $0.58 \pm 0.51$ to $15.58 \pm 3.00$ and maximum heart rate during testing decreased from $160.1 \pm 7.7$ to $126.9 \pm 8.8 \mathrm{bpm}$ ( $\mathrm{p}<.05$ ). The improvement in backstroke proficiency in both groups can been grounded, as multiplied repetition of the same movements usually results in mastering those skills (Taubert et al., 2010; Landi, Baguear \& Della-Maggiore, 2011). The examined groups in the present study were different from those in the available literature, but the study of Oh et al., (2008) also suggested significant change between the time periods for front crawl and backstroke teaching across 10 lessons $\times 30 \mathrm{~min} /$ week in children with Developmental Coordination Disorder $(\mathrm{p}<.05)$.

The obtained results showed that the significant improvement of backstroke proficiency in first group accompanies only with progress in BM proficiency components (from $28.65 \pm 3.67$ to $42.92 \pm 4.12$ points) and does not show a child's ability to perform common pattern of coordination (from $3.00 \pm 0.00$ to $3.58 \pm 0.29$ points) after the teaching pattern of backstroke movements separate components. Besides this, there is no evidences how many lessons it takes to develop such skill without direct teaching. In contrast, children in second group demonstrated significant progress both in BM (from $29.42 \pm 3.70$ to $40.5 \pm 3.5$ points) as well as BC (from $3.00 \pm 0.00$ to $11.25 \pm 1.36$ points) components of proficiency. The results of the present study suggest that direct teaching arm-to-leg diagonal interaction provides the ability to acquire a common pattern of backstroke coordination in healthy children with RPR after 12 lessons of teaching. Post-teaching backstroke proficiency test defined that 9 participants, or $75 \%$ from second group, demonstrated the ability to perform the common form of arm-to-leg diagonal interaction pattern all the time and another 3 children, or $25 \%$ of participants, also showed an ability to combine arm-to-leg isolated movements into common pattern of coordination most of the time. In the first group, the teaching method of backstroke separate movement's components was used with the expectation that it would provide the ability to acquire common pattern of backstroke 
coordination through trial and error. This part practice method is used by researchers and widely recommended in swimming textbooks. This approach based on the evidence, that humans have the persistent preservation of the neuronal connections between their upper limbs and lower limbs, also called interlimb reflex responses, that coordinate contralateral muscle activation patterns during locomotion (Zehr et al., 2016; Kerkman, Bekius, Boonstra, Daffertshofer, \& Dominici, 2020). During swimming, crawling and walking the upper limbs and lower limbs preserve common pattern of coordination (Wannier, Bastiaanse, Colombo, \& Dietz, 2001) which include a diagonal interlimb interaction where the limbs (e.g., arms and legs) on contralateral sides of the body move in unison (Adolph, Vereijken \& Denny, 1998; Patrick, Noah, \& Yang, 2009). Because the arm movement used in backstroke swimming is not pendularlike, it requires more active nervous system control compared to walking. However, even with increased neural control, the basic arm-to-leg pattern of coordination is preserved (Wannier et al., 2001). Unfortunately, studies on common pattern of coordination in children during learning of swimming strokes were not conducted by the academic community. There are also no studies about the direct teaching arm-to-leg interaction in healthy children with residual primitive reflexes. Nevertheless, Lerda, Cardelli, \& Coudereau, (2005) examined backstroke organization in physical education students and concluded that only $52.8 \%$ of 36 students after 20 weeks (twice in a week) of training to swim demonstrated common pattern of coordination during backstroke swimming. Additionally, Bruijn et al., 2013, conducted a study on primitive reflexes in healthy adults. It was found that all ten subjects participated in the study had residual primitive reflexes (Bruijn et al., 2013). Therefore, present study provokes an assumption that interlimb reflex responses during swimming could be constrained by residual primitive reflexes. In this case, acquisition common pattern of backstroke coordination will be complicated.

It would be important to say that despite significant improvement in backstroke swimming, both groups, after twelve weeks of teaching, demonstrated differences between backstroke skilled actions components. The best results have been demonstrated by children with RPR taught by part practice method aimed at ability to perform common pattern of backstroke coordination. The better results of BP (51.75 \pm 4.58 vs. $46.5 \pm 4.54$; Cochen's d: 1.15$)$ were linked with BC (3.58 \pm 0.29 vs. $11.25 \pm 1.36$; Cochen's d: 7.82 ), which is evidence of ability to perform the common pattern of backstroke coordination; Dmax (15.58 \pm 3.00 vs. 7.92 \pm 2.43$)$; Cochen's d: 2.80), reflecting the ability to swim longer distances; and HR (126.92 \pm 8.83 vs. $154.25 \pm 5.05$; Cochen's d: 3.8$)$, correspondent to the lower level of intensity during backstroke swimming. There is no evidence about the effect of teaching methods and common pattern of backstroke coordination in healthy children with RPR, but the results of present study also could be echoed 
by study of Wilson, Simpson, van Emmerik, \& Hamill (2008). They stated that performance in triple jump athletes improved only after the appropriate characteristics defining the movement coordination patterns had been acquired. Refinement of these characteristics resulted in a more consistent and regulated movement. This ability brings flexibility to the motor system allowing it to cope with perturbations (Wilson et al., 2008). The quantitative evaluation of arm-to-leg coordination also confirm that front crawl swimming consists of an integral rational sequential system of movements with the bilateral interaction between arms and legs and the higher level technique corresponds with the ability to show values more closely to the in-phase mode of coordination during performing common patterns of coordination (Martínez-Sobrino et al., 2017). Anothers studies also identified that a loss of co-ordination, or range of motion within the kinetic chain can result in a sub-optimal performance (Roy, Moffet, \& McFadyen, 2008; Myer et al., 2014).

Based on the analysis of present study, it was defined that for healthy children with residual primitive reflexes both the higher level of consistency as well as significantly better effectivity of backstroke skilled movement is provided by directed teaching of arm-to-leg diagonal interaction combined with breathing control. There is no direct evidence in the existing literature to suggest such statement, nevertheless, it is important to mention that, the main reference point for performing any voluntary movements on the ground (under gravity) is postural control. Postural control developed in the early stages of ontogenesis includes the ability to automatically (unconsciously) without the involvement of cognitive processing restore and maintain a stable vertical position when interacting with the environment during walking. Maintaining vertical balance is vitally important for developing children, because it provides a base on which to learn other skills (Hadders-Algra, 2005; 2018). The holding horizontal body (trunk) position in unusual physical environment during backstroke learning is the situation when the postural response is not necessarily helpful in the execution of a task. Moreover, postural control might complicate learning to swim (Geuze, 2003; Wann, Mon-Williams, \& Rushtion, 1998). The studies indicate that automated postural responses occur when balance is perturbed, irrespective of whether performers are instructed to recover or not to recover balance (Weerdesteyn, Laing, \& Robinovitch, 2008). In this context, swimming stroke learning is the situation during which child performs two tasks simultaneously: 1. controls balance in horizontal body position in water and 2. executes complex motor task. Balance control is critical to the learning of complex motor skills and the execution of coordinated motor behaviors (Chen \& Woollacott, 2007). Poor balance in the water will decrease the efficiency of limbs movements in an attempt to gain stability (Toussaint, Van den Berg, \& Beek, 2002). The problem with the concept of duality is based on the assumption that the brain has limited 
information-processing capacity, which is why a decrement in performance of one or both tasks can be observed (Mitra, Knight, \& Munn, 2013; Huxhold, Li, Schmiedek, \& Lindenberg, 2006; Legrand et al., 2013). In addition, the existence of primitive reflexes also interferes with the children's ability to effectively integrate both sides of the body (Blythe, 2009, 2011), which is crucial in swimming stroke skill acquisition. In this context, part practice method aimed on teaching common pattern of backstroke coordination gives better results in children with RPR, because the ability to execute arm-to-leg diagonal interaction automatically provides the balance and stability (Patrick et al., 2009; Righetti, Nylén, Rosander, \& Ijspeert, 2015), reducing cognitive load during backstroke learning.

\section{Conclusions}

The papers in the area of motor skill learning are usually linked with teaching of specialised sport skill movement which is based on fundamental movement, where both postural control, aimed on verticality, as well as automatic control of voluntary movement plays a crucial role. Due to different teaching environments, the results of such studies could not be applied as a recommendation for effective swimming learning. In this study, the use of healthy children with RPR during swimming stroke teaching is interesting because these questions are dropped out of researchers' focus of attention. The data of present study found that during backstroke learning part practice, teaching method aimed at common pattern of coordination benefits greatly in backstroke swimming proficiency improvement over part practice teaching method focused on pattern of movements in children with residual primitive reflexes. However, several limitations affect the interpretations of these results. First, due to absent the information about this theme in the available literature, the results and subsequent conclusions of this study are limited to the expert performer who participated in the study. The results should be replicated by other studies. Second, the data lacks a control group for comparison. With a number of participants without primitive reflexes, it may be that different results would better evaluate the methods of swimming teaching impact on swimming skill acquisition by healthy children with residual primitive reflexes. Thirdly, is the small sample size the statistical power and consequently the significance of results are decreased. The effect size was used to better control and analysis of the differences obtained. Additionally, the number of participants during lessons has been reduced to two to provide more effective teaching. Other key factors that had an influence on the backstroke teaching-learning results in healthy children with residual primitive reflexes could be the acquisition of skilled action in shallow water. Thus, the results derived from this study should be interpreted cautiously and confirmed by further investigations. 
Bogdanovica \& Larins, 2021. Backstroke Teaching Methods in Healthy Children with Residual Primitive Reflexes

\section{References}

Adolph, K. E., Vereijken, B., \& Denny, M. A. (1998). Learning to crawl. Child development, 69(5), 1299-1312.

Ardila, A., Rosselli, M., Matute, E., \& Inozemtseva, O. (2011). Gender differences in cognitive development. Developmental psychology, 47(4), 984-990. https://doi.org/10.1037/ a0023819

Bilbilaj, S., Gjipali, A., \& Shkurti, F. (2017). Measuring Primitive Reflexes in Children with Learning Disorders. European Journal of Multidisciplinary Studies, 2(5), 285-298. ISSN 2414-8385

Blanksby, B. A., Parker, H. E., Bradley, S., \& Ong, V. (1995). Children's readiness for learning front crawl swimming. Australian Journal of Science and Medicine in Sport, 27(2), 3437.

Blythe, S. G. (2009). Attention, Balance and Coordination: The A.B.C. of Learning Success. Wiley-Blackwell.

Blythe, S. G. (2011). Neuro-motor maturity as an indicator of developmental readiness for education. TAC Journal, 4(12), 1-12. Retrieved from http://www.novreflextherapie.nl/ pdf-bestanden/bibliotheek-neuro-motor.pdf

Bruijn, S. M., Massaad, F., Maclellan, M. J., Van Gestel, L., Ivanenko, Y. P., \& Duysens, J. (2013). Are effects of the symmetric and asymmetric tonic neck reflexes still visible in healthy adults? Neuroscience letters, 556, 89-92. https://doi.org/10.1016/j.neulet. 2013.10.028

Chen, J., \& Woollacott, M. H. (2007). Lower extremity kinetics for balance control in children with cerebral palsy. Journal of motor behavior, 39(4), 306-316. https://doi.org/ 10.3200/JMBR.39.4.306-316

Cohen, J. (1988). Statistical power analysis for the behavioral sciences. Hillsdale, NJ: Lawrence Earlbaum Associates.

Invernizzi, P. L., Scurati, R., Roione, G. C., \& Michielon, G. (2006). Swimming and training: Comparison between heuristic and prescriptive learning. Biomechanics and Medicine in Swimming X, 6(2), 227-229.

Fleming, S., Thompson, M., Stevens, R., Heneghan, C., Plüddemann, A., Maconochie, I., Tarassenko, L., \& Mant, D. (2011). Normal ranges of heart rate and respiratory rate in children from birth to 18 years of age: a systematic review of observational studies. Lancet (London, England), 377(9770), 1011-1018. https://doi.org/10.1016/S01406736(10)62226-X

Fontana, F. E., Mazzardo, O., Furtado, O., Jr, \& Gallagher, J. D. (2009). Whole and part practice: a meta-analysis. Perceptual and motor skills, 109(2), 517-530. https://doi.org/ 10.2466/PMS.109.2.517-530

Franklin, R. C., Peden, A. E., Hodges, S., Lloyd, N., Larsen, P., O'Connor, C., \& Scarr, J. (2015). Learning to Swim: What Influences Success? International Journal of Aquatic Research and Education, 9(3), 220-240. DOI:10.25035/ijare.09.03.02

Geuze, R. H. (2003). Static balance and developmental coordination disorder. Human movement science, 22(4-5), 527-548. https://doi.org/10.1016/j.humov.2003.09.008

Gieysztor, E. Z., Choińska, A. M., \& Paprocka-Borowicz, M. (2018). Persistence of primitive reflexes and associated motor problems in healthy preschool children. Arch Med Sci, 14(1), 167-173. DOI: 10.5114/aoms.2016.60503

Gieysztor, E. Z., Sadowska, L., \& Choińska, A. M. (2017). The degree of primitive reflexes integration as a diagnostic tool to assess the neurological maturity of healthy preschool 
and early school age children. Pielegniarstwo i Zdrowie Publiczne, 26(1), 5-11. Retrieved from ISSN 2082-9876 (print), ISSN 2451-1870 (online)

Gomez, A., \& Sirigu, A. (2015). Developmental coordination disorder: core sensori-motor deficits, neurobiology and etiology. Neuropsychologia, 79(Pt B), 272-287. https://doi.org/10.1016/j.neuropsychologia.2015.09.032

Hadders-Algra, M. (2005). Development of postural control during the first 18 months of life. Neural Plas, 12, 99-108.

Hadders-Algra, M. (2018). Early human motor development: From variation to the ability to vary and Adapt. Neuroscience and Biobehavioral Reviews, 90(7), 411-427. https://doi.org/10.1016/j.neubiorev.2018.05.009

Huxhold, O., Li, S. C., Schmiedek, F., \& Lindenberger, U. (2006). Dual-tasking postura control: aging and the effects of cognitive demand in conjunction with focus of attention. Brain research bulletin, 69(3), 294-305. https://doi.org/10.1016/j.brainresbull.2006.01.002

Kerkman, J. N., Bekius, A., Boonstra, T. W., Daffertshofer, A., \& Dominici, N. (2020). Muscle Synergies and Coherence Networks Reflect Different Modes of Coordination During Walking. Frontiers in physiology, 11, 751. https://doi.org/10.3389/fphys.2020.00751

Krzeszewska, P., \& Mikołajewska, E. (2018). Coexistence of Preserved Primary Reflexes and Speech-Language Disorders in Children - State-of-the-Art. Logopedia, 47(1), 39-49.

Landi, S. M., Baguear, F., \& Della-Maggiore, V. (2011). One week of motor adaptation induces structural changes in primary motor cortex that predict long-term memory one year later. Journal of Neuroscience, 31(33), 11808-11813. doi:10.1523/JNEUROSCI.225311.2011.

Langendorfer, S. J. (2007). The Developmental Perspective, the Swimming Reflex, and The Velveteen Rabbit. International Journal of Aquatic Research and Education, 1(2). DOI: 10.25035/ijare.01.02.01

Legrand, A., Mazars, K. D., Lazzareschi, J., Lemoine, C., Olivier, I., Barra, J., \& Bucci, M. P. (2013). Differing effects of prosaccades and antisaccades on postural stability. Experimental brain research, 227(3), 397-405. https://doi.org/10.1007/s00221-0133519-z

Lerda, R., Cardelli, C., \& Coudereau, J. P. (2005). Backstroke organization in physical education students as a function of skill and sex. Perceptual and motor skills, 100 (3 Pt 1), 779-790. https://doi.org/10.2466/pms.100.3.779-790

Magill, R. A., \& Anderson, D. (2016). Motor learning and control: Concepts and applications (11th ed.). New York: McGraw-Hill.

Maglischo, E. (2003). Swimming fastest. Human Kinetics Champaign, Illinois, ISBN: 0736031804

Martínez-Sobrino, J., Veiga, S., \& Navandar, A. (2017). Evaluation of arm-to-leg coordination in freestyle swimming. European Journal of Human Movement, 38, 27-39.

Mitra, S., Knight, A., \& Munn, A. (2013). Divergent effects of cognitive load on quiet stance and task-linked postural coordination. Journal of experimental psychology. Human perception and performance, 39(2), 323-328. https://doi.org/10.1037/a0030588

Muratori, L. M., Lamberg, E. M., Quinn, L., \& Duff, S. V. (2013). Applying principles of motor learning and control to upper extremity rehabilitation. Journal of hand therapy: official journal of the American Society of Hand Therapists, 26(2), 94-103. https://doi.org/ 10.1016/j.jht.2012.12.007

Myer, G. D., Kushner, A. M., Brent, J. L., Schoenfeld, B. J., Hugentobler, J., Lloyd, R. S., Vermeil, A., Chu, D. A., Harbin, J., \& McGill, S. M. (2014). The back squat: A proposed 
assessment of functional deficits and technical factors that limit performance. Strength and conditioning journal, 36(6), 4-27. https://doi.org/10.1519/SSC.0000000000000103

Oh, S., Licari, M., Lay, B., \& Blanksby, B. (2011). Effects of Teaching Methods on Swimming Skill Acquisition in Children with Developmental Coordination Disorder. International Journal of Aquatic Research and Education, 5(4), 432-448. DOI: 10.25035/ijare.05.04.09

Patrick, S. K., Noah, J. A., \& Yang, J. F. (2009). Interlimb coordination in human crawling reveals similarities in development and neural control with quadrupeds. Journal of neurophysiology, 101(2), 603-613. https://doi.org/10.1152/jn.91125.2008

Pecuch, A., Gieysztor, E., Telenga, M., Wolańska, E., Kowal, M., \& Paprocka-Borowicz, M. (2020). Primitive Reflex Activity in Relation to the Sensory Profile in Healthy Preschool Children. International journal of environmental research and public health, 17(21), 8210. https://doi.org/10.3390/ijerph17218210

Polimac, M., Vukadinovic, M., \& Obradovic, J. (2013) Differences in motor abilities of children in relation to gender and age. Exercise and quality of life. 5(2), 28-33. UDC: 796.012.1-053.2

Revesz, L., Bognar, J., Salvara, M. I., Gita, S., \& Biro, M. (2007). Curriculum Development for Teaching Swimming in Hungary. International Journal of Aquatic Research and Education, 1(2), 156-165. DOI: 10.25035/ijare.01.02.07

Riewald, S., \& Rodeo, S. (2015). Science of swimming faster. Human Kinetics Champaign, IL, United States. ISBN13 9780736095716

Righetti, L., Nylén, A., Rosander, K., \& Ijspeert, A. J. (2015). Kinematic and Gait Similarities between Crawling Human Infants and Other Quadruped Mammals. Frontiers in neurology, 6, 17. https://doi.org/10.3389/fneur.2015.00017

Roy, J. S., Moffet, H., \& McFadyen, B. J. (2008). Upper limb motor strategies in persons with and without shoulder impingement syndrome across different speeds of movement. Clinical biomechanics (Bristol, Avon), 23(10), 1227-1236.

Schott, J. M., \& Rossor, M. N. (2003). The grasp and other primitive reflexes. J. Neurol. Neurosurg. Psychiatry, 74(5), 558-560. https://jnnp.bmj.com/content/74/5/558

Sharma, A., Ford, S., \& Calvert, J. (2014). Adaptation for life: a review of neonatal physiology. Anaesthesia and intensive care medicine, 15(3), 89-95. Retrieved from https://doi.org/10.1016/j.mpaic.2014.01.002

Sohn, M., Ahn, Y., Lee, S. (2011). Assessment of Primitive Reflexes in High-risk Newborns, J Clin Med Res, 3(6), 285-290.

Taubert, M., Draganski, B., Anwander, A., Müller, K., Horstmann, A., Villringer, A., \& Ragert, P. (2010). Dynamic Properties of Human Brain Structure: Learning- Related Changes in Cortical Areas and Associated Fiber Connections. The Journal of Neuroscience, 30(35), 11670 -11677. Retrieved from https://doi.org/10.1523/JNEUROSCI.2567-10.2010

Toussaint, H. M., Van den Berg, C., \& Beek, W. J. (2002). "Pumped-up propulsion" during front crawl swimming. Medicine and science in sports and exercise, 34(2), 314-319. https://doi.org/10.1097/00005768-200202000-00020

Walliman, N. (2011). Research methods: the basics. Routledge. ISBN 0-203-83607-3 Master e-book ISBN

Wann, J.P., Mon-Williams, M., \& Rushtion, K. (1998). Postural control and coordination disorders: The swinging room revisited. Human Movement Science, 17, 491-513.

Wannier, T., Bastiaanse, C., Colombo, G., \& Dietz, V. (2001). Arm to leg coordination in humans during walking, creeping and swimming activities. Experimental brain research, 141(3), 375-379. https://doi.org/10.1007/s002210100875 
Weerdesteyn, V., Laing, A. C., \& Robinovitch, S. N. (2008). Automated postural responses are modified in a functional manner by instruction. Experimental brain research, 186(4), 571-580. https://doi.org/10.1007/s00221-007-1260-1

Wilson, C., Simpson, S. E., van Emmerik, R. E., \& Hamill, J. (2008). Coordination variability and skill development in expert triple jumpers. Sports biomechanics, 7(1), 2-9. https://doi.org/10.1080/14763140701682983

Wulf, G., \& Shea, C.H. (2002). Principles derived from the study of simple skills do not generalize to complex skill learning. Psychonomic Bulletin \& Review, 9(2), 185-211. DOI: 10.3758/BF03196276

Zafeiriou, D. (2004). Primitive reflexes and postural reactions in the neurodevelopmental examination. Pediatr Neurol, 31(1), 1-8. DOI:10.1016/j.pediatrneurol.2004.01.012

Zehr, E. P., Barss, T. S., Dragert, K., Frigon, A., Vasudevan, E. V., Haridas, C., Hundza, S., Kaupp, C., Klarner, T., Klimstra, M., Komiyama, T., Loadman, P. M., Mezzarane, R. A., Nakajima, T., Pearcey, G. E., \& Sun, Y. (2016). Neuromechanical interactions between the limbs during human locomotion: an evolutionary perspective with translation to rehabilitation. Experimental brain research, 234(11), 3059-3081. 